\title{
Fixed Point Theorems for Hybrid Rational Geraghty Contractive Mappings in Ordered b-Metric Spaces
}

\author{
Farzaneh Zabihi $^{1}$ and Abdolrahman Razani ${ }^{2}$ \\ ${ }^{1}$ Department of Mathematics, College of Science, Islamic Azad University, Tehran Science and Research Branch, Tehran, Iran \\ ${ }^{2}$ Department of Mathematics, Faculty of Science, Imam Khomeini International University, P.O. Box 34194-16818, Qazvin, Iran
}

Correspondence should be addressed to Farzaneh Zabihi; f.zabihi80@yahoo.com

Received 3 September 2013; Revised 3 March 2014; Accepted 17 March 2014; Published 24 April 2014

Academic Editor: Vu Ngoc Phat

Copyright (C) 2014 F. Zabihi and A. Razani. This is an open access article distributed under the Creative Commons Attribution License, which permits unrestricted use, distribution, and reproduction in any medium, provided the original work is properly cited.

We introduce the new notion of a hybrid rational Geraghty contractive mapping and investigate the existence of fixed point and coincidence point for such mappings in ordered $b$-metric spaces. We also provide an example to illustrate the results presented herein. Finally, we establish an existence theorem for a solution of an integral equation.

\section{Introduction}

Recently, many researchers have focused on different contractive conditions in complete metric spaces endowed with a partial order and obtained many fixed point results in such spaces. For more details on fixed point results, their applications, comparison of different contractive conditions, and related results in ordered metric spaces, we refer the reader to [1-4].

The concept of a $b$-metric space was introduced by Czerwik in [5]. After that, several interesting results about the existence of fixed points for single-valued and multivalued operators in $b$-metric spaces have been obtained (see, e.g., [6$11]$ and $[12-15])$.

Definition 1 (see [5]). Let $X$ be a (nonempty) set and let $s \geq 1$ be a given real number. A function $d: X \times X \rightarrow R^{+}$is a $b$-metric if for all $x, y, z \in X$, the following conditions are satisfied:

$\left(b_{1}\right) d(x, y)=0$ iff $x=y$,

$\left(b_{2}\right) d(x, y)=d(y, x)$,

$\left(b_{3}\right) d(x, z) \leq s[d(x, y)+d(y, z)]$.

The pair $(X, d)$ is called a $b$-metric space.
A $b$-metric is a metric if (and only if) $s=1$. The following example shows that in general a $b$-metric need not to be a metric.

Example 2 (see [16]). Let $(X, d)$ be a metric space, and $\rho(x, y)=(d(x, y))^{p}$, where $p \geq 1$ is a real number. Then, $\rho$ is a $b$-metric with $s=2^{p-1}$.

However, $(X, \rho)$ is not necessarily a metric space. For example, if $X=\mathbb{R}$ is the set of real numbers and $d(x, y)=$ $|x-y|$ is the usual metric, then $\rho(x, y)=(x-y)^{2}$ is a $b$ metric on $\mathbb{R}$ with $s=2$, but it is not a metric on $\mathbb{R}$.

Definition 3 (see [17]). Let $(X, d)$ be a $b$-metric space. Then, a sequence $\left\{x_{n}\right\}$ in $X$ is called

(a) $b$-convergent if and only if there exists $x \in X$ such that $d\left(x_{n}, x\right) \rightarrow 0$, as $n \rightarrow \infty$ and in this case, we write $\lim _{n \rightarrow \infty} x_{n}=x$.

(b) b-Cauchy if and only if $d\left(x_{n}, x_{m}\right) \rightarrow 0$, as $n, m \rightarrow$ $\infty$

Proposition 4 (see Remark 2.1 in [17]). In a b-metric space $(X, d)$, the following assertions hold.

$\left(p_{1}\right)$ A b-convergent sequence has a unique limit.

$\left(p_{2}\right)$ Each b-convergent sequence is b-Cauchy.

$\left(p_{3}\right)$ In general, a b-metric is not continuous. 
The $b$-metric space $(X, d)$ is $b$-complete if every $b$-Cauchy sequence in $X$ is $b$-convergent.

Note that a $b$-metric might not be a continuous function. The following example (corrected from [18]) illustrates this fact.

Example 5. Let $X=\mathbb{N} \cup\{\infty\}$ and let $d: X \times X \rightarrow \mathbb{R}$ be defined by

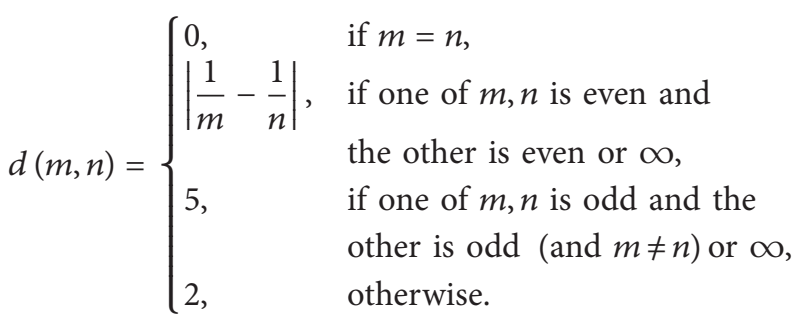

Then, considering all possible cases, it can be checked that for all $m, n, p \in X$, we have

$$
d(m, p) \leq \frac{5}{2}(d(m, n)+d(n, p))
$$

Thus, $(X, d)$ is a $b$-metric space (with $s=5 / 2$ ). Let $x_{n}=2 n$ for each $n \in \mathbb{N}$. Then

$$
d(2 n, \infty)=\frac{1}{2 n} \longrightarrow 0 \quad \text { as } n \longrightarrow \infty ;
$$

that is, $x_{n} \rightarrow \infty$, but $d\left(x_{n}, 1\right)=2 \nrightarrow 5=d(\infty, 1)$ as $n \rightarrow \infty$.

Lemma 6 (see $[16])$. Let $(X, d)$ be a $b$-metric space with $s \geq 1$, and suppose that $\left\{x_{n}\right\}$ and $\left\{y_{n}\right\}$ are $b$-convergent to $x, y$, respectively. Then, we have

$$
\begin{aligned}
\frac{1}{s^{2}} d(x, y) & \leq \liminf _{n \rightarrow \infty} d\left(x_{n}, y_{n}\right) \\
& \leq \limsup _{n \rightarrow \infty} d\left(x_{n}, y_{n}\right) \leq s^{2} d(x, y) .
\end{aligned}
$$

In particular, if $x=y$, then we have $\lim _{n \rightarrow \infty} d\left(x_{n}, y_{n}\right)=0$. Moreover, for each $z \in X$, we have

$$
\begin{aligned}
\frac{1}{s} d(x, z) & \leq \liminf _{n \rightarrow \infty} d\left(x_{n}, z\right) \\
& \leq \limsup _{n \rightarrow \infty} d\left(x_{n}, z\right) \leq s d(x, z) .
\end{aligned}
$$

Let $\mathfrak{\subseteq}$ denote the class of all real functions $\beta:[0,+\infty) \rightarrow$ $[0,1)$ satisfying the condition

$$
\beta\left(t_{n}\right) \longrightarrow 1 \text { implies } t_{n} \longrightarrow 0, \quad \text { as } n \longrightarrow \infty \text {. }
$$

In order to generalize the Banach contraction principle, Geraghty in 1973 proved the following.

Theorem 7 (see [19]). Let $(X, d)$ be a complete metric space, and let $f: X \rightarrow X$ be a self-map. Suppose that there exists $\beta \in \mathbb{S}$ such that

$$
d(f x, f y) \leq \beta(d(x, y)) d(x, y)
$$

holds for all $x, y \in X$. Then, f has a unique fixed point $z \in X$ and for each $x \in X$ Picard's sequence $\left\{f^{n} x\right\}$ converges to $z$.
In 2010, Amini-Harandi and Emami [20] characterized the result of Geraghty in the framework of a partially ordered complete metric space in the following way.

Theorem 8. Let $(X, d, \preceq)$ be a complete partially ordered metric space. Let $f: X \rightarrow X$ be an increasing self-map such that there exists $x_{0} \in X$ with $x_{0} \preceq f x_{0}$. Suppose that there exists $\beta \in \mathbb{S}$ such that

$$
d(f x, f y) \leq \beta(d(x, y)) d(x, y)
$$

holds for all $x, y \in X$ with $y \preceq x$. Assume that either $f$ is continuous or $X$ is such that if an increasing sequence $\left\{x_{n}\right\}$ in $X$ converges to $x \in X$, then $x_{n} \preceq x$ for all $n$. Then, $f$ has a fixed point in $X$. If, moreover, for each $x, y \in X$ there exists $z \in X$ comparable with $x, y$, then the fixed point of $f$ is unique.

Cabellero et al. [21] discussed the existence of a best proximity point of Geraghty contraction. In [22], some fixed point theorems for mappings satisfying Geraghty-type contractive conditions are proved in various generalized metric spaces. As in [22], we will consider the class of functions $\mathscr{F}$, where $\beta \in \mathscr{F}$ if $\beta:[0, \infty) \rightarrow[0,1 / s)$ and has the property

$$
\beta\left(t_{n}\right) \longrightarrow \frac{1}{s} \text { implies } t_{n} \longrightarrow 0, \quad \text { as } n \longrightarrow \infty \text {. }
$$

Theorem 9 (see [22]). Let $s>1$, and let $(X, D, s)$ be a complete metric type space. Suppose that a mapping $f: X \rightarrow X$ satisfies the condition

$$
D(f x, f y) \leq \beta(D(x, y)) D(x, y),
$$

for all $x, y \in X$ and some $\beta \in \mathscr{F}$. Then $f$ has a unique fixed point $z \in X$, and for each $x \in X$ Picard's sequence $\left\{f^{n} x\right\}$ converges to $z$ in $(X, D, K)$.

The aim of this paper is to present some fixed point and coincidence point theorems for hybrid rational Geraghty contractive mappings in partially ordered $b$-metric spaces. In fact, our results extend Theorems 7, 8, and 9.

\section{Main Results}

Let $\mathscr{F}$ denote the class of all functions $\beta:[0, \infty) \rightarrow[0,1 / s)$ satisfying the following condition:

$$
\beta\left(t_{n}\right) \longrightarrow \frac{1}{s} \text { implies } t_{n} \longrightarrow 0, \quad \text { as } n \longrightarrow \infty .
$$

Theorem 10. Let $(X, \preceq)$ be a partially ordered set and suppose that there exists a $b$-metric $d$ on $X$ such that $(X, d)$ is a complete $b$-metric space (with parameter $s>1$ ). Let $f: X \rightarrow X$ be an increasing mapping with respect to $\preceq$ such that there exists an element $x_{0} \in X$ with $x_{0} \preceq f\left(x_{0}\right)$. Suppose that

$$
s d(f x, f y) \leq \beta(d(x, y)) M(x, y)+L N(x, y)
$$

for all comparable elements $x, y \in X$, where $L \geq 0$,

$$
\begin{gathered}
M(x, y)=\max \left\{d(x, y), \frac{d(x, f x) d(y, f y)}{1+d(f x, f y)}\right\}, \\
N(x, y)=\min \{d(x, f x), d(x, f y), d(y, f x), d(y, f y)\} .
\end{gathered}
$$


If $f$ is continuous, then $f$ has a fixed point. Moreover, the set of fixed points of $f$ is well ordered if and only if $f$ has one and only one fixed point.

Proof. Put $x_{n}=f^{n}\left(x_{0}\right)$. Since $x_{0} \preceq f\left(x_{0}\right)$ and $f$ is an increasing function, we obtain by induction that

$$
x_{0} \preceq f\left(x_{0}\right) \preceq f^{2}\left(x_{0}\right) \preceq \cdots \preceq f^{n}\left(x_{0}\right) \preceq f^{n+1}\left(x_{0}\right) \preceq \cdots .
$$

Step 1. We will show that $\lim _{n \rightarrow \infty} d\left(x_{n}, x_{n+1}\right)=0$. Since $x_{n} \preceq$ $x_{n+1}$ for each $n \in N$, then by (12), we have

$$
\begin{aligned}
s d & \left(x_{n}, x_{n+1}\right) \\
& =s d\left(f x_{n-1}, f x_{n}\right) \\
& \leq \beta\left(d\left(x_{n-1}, x_{n}\right)\right) M\left(x_{n-1}, x_{n}\right)+L N\left(x_{n-1}, x_{n}\right) \\
& \leq \beta\left(d\left(x_{n-1}, x_{n}\right)\right) d\left(x_{n-1}, x_{n}\right) \\
& <\frac{1}{s} d\left(x_{n-1}, x_{n}\right) \\
& \leq d\left(x_{n-1}, x_{n}\right),
\end{aligned}
$$

because

$$
\begin{aligned}
M & \left(x_{n-1}, x_{n}\right) \\
& =\max \left\{d\left(x_{n-1}, x_{n}\right), \frac{d\left(x_{n-1}, f x_{n-1}\right) d\left(x_{n}, f x_{n}\right)}{1+d\left(f x_{n-1}, f x_{n}\right)}\right\} \\
& =\max \left\{d\left(x_{n-1}, x_{n}\right), \frac{d\left(x_{n-1}, x_{n}\right) d\left(x_{n}, x_{n+1}\right)}{1+d\left(x_{n}, x_{n+1}\right)}\right\} \\
& =d\left(x_{n-1}, x_{n}\right), \\
N & \left(x_{n-1}, x_{n}\right) \\
& =\min \left\{d\left(x_{n-1}, f x_{n}\right), d\left(x_{n}, f x_{n}\right),\right. \\
& =\min \left\{d\left(x_{n-1}, x_{n+1}\right), d\left(x_{n}, x_{n+1}\right),\right. \\
& \left.=0 . \quad d\left(x_{n-1}, x_{n}\right), d\left(x_{n}, x_{n}\right)\right\}
\end{aligned}
$$

Therefore, $\left\{d\left(x_{n}, x_{n+1}\right)\right\}$ is decreasing. Then there exists $r \geq 0$ such that $\lim _{n \rightarrow \infty} d\left(x_{n}, x_{n+1}\right)=r$. We will prove that $r=0$. Suppose on contrary that $r>0$. Then, letting $n \rightarrow \infty$ from (15), we have

$$
s r \leq \lim _{n \rightarrow \infty} \beta\left(d\left(x_{n-1}, x_{n}\right)\right) r<r
$$

which implies that $s<1$, a contradiction. Hence, $r=0$. That is,

$$
\lim _{n \rightarrow \infty} d\left(x_{n-1}, x_{n}\right)=0 .
$$

Step 2. Now, we prove that the sequence $\left\{x_{n}\right\}$ is a $b$-Cauchy sequence. Suppose the contrary; that is, $\left\{x_{m}\right\}$ is not a $b$ Cauchy sequence. Then, there exists $\varepsilon>0$ for which we can find two subsequences $\left\{x_{m_{i}}\right\}$ and $\left\{x_{n_{i}}\right\}$ of $\left\{x_{n}\right\}$ such that $n_{i}$ is the smallest index for which

$$
n_{i}>m_{i}>i, \quad d\left(x_{m_{i}}, x_{n_{i}}\right) \geq \varepsilon .
$$

This means that

$$
d\left(x_{m_{i}}, x_{n_{i}-1}\right)<\varepsilon .
$$

From (19) and using the triangular inequality, we get

$$
\varepsilon \leq d\left(x_{m_{i}}, x_{n_{i}}\right) \leq s d\left(x_{m_{i}}, x_{m_{i}+1}\right)+s d\left(x_{m_{i}+1}, x_{n_{i}}\right) .
$$

By taking the upper limit as $i \rightarrow \infty$, we get

$$
\frac{\varepsilon}{\mathcal{s}} \leq \limsup _{i \rightarrow \infty} d\left(x_{m_{i}+1}, x_{n_{i}}\right) .
$$

Using the triangular inequality, we have

$$
d\left(x_{m_{i}}, x_{n_{i}}\right) \leq s d\left(x_{m_{i}}, x_{n_{i}-1}\right)+s d\left(x_{n_{i}-1}, x_{n_{i}}\right) .
$$

Taking the upper limit as $i \rightarrow \infty$ in the above inequality and using (20), we get

$$
\limsup _{i \rightarrow \infty} d\left(x_{m_{i}}, x_{n_{i}}\right) \leq \varepsilon s .
$$

From the definition of $M(x, y)$ and $N(x, y)$ and the above limits, we have

$$
\begin{aligned}
& \limsup _{i \rightarrow \infty} M\left(x_{m_{i}}, x_{n_{i}-1}\right) \\
& =\limsup _{i \rightarrow \infty} \max \left\{d\left(x_{m_{i}}, x_{n_{i}-1}\right),\right. \\
& \left.\qquad \frac{d\left(x_{m_{i}}, f x_{m_{i}}\right) d\left(x_{n_{i}-1}, f x_{n_{i}-1}\right)}{1+d\left(f x_{m_{i}}, f x_{n_{i}-1}\right)}\right\} \\
& =\limsup _{i \rightarrow \infty}\left\{d\left(x_{m_{i}}, x_{n_{i}-1}\right), \frac{d\left(x_{m_{i}}, x_{m_{i}+1}\right) d\left(x_{n_{i}-1}, x_{n_{i}}\right)}{1+d\left(x_{m_{i}+1}, x_{n_{i}}\right)}\right\}, \\
& \leq \varepsilon,
\end{aligned}
$$

$\limsup _{i \rightarrow \infty} N\left(x_{m_{i}}, x_{n_{i}-1}\right)$

$$
\begin{gathered}
=\limsup _{i \rightarrow \infty} \min \left\{d\left(x_{m_{i}}, f x_{m_{i}}\right), d\left(x_{m_{i}}, f x_{n_{i}-1}\right),\right. \\
\left.d\left(x_{n_{i}-1}, f x_{m_{i}}\right), d\left(x_{n_{i}-1}, f x_{n_{i}-1}\right)\right\} \\
=\limsup _{i \rightarrow \infty} \min \left\{d\left(x_{m_{i}}, x_{m_{i}+1}\right), d\left(x_{m_{i}}, x_{n_{i}}\right),\right. \\
\left.d\left(x_{n_{i}-1}, x_{m_{i}+1}\right), d\left(x_{n_{i}-1}, x_{n_{i}}\right)\right\}
\end{gathered}
$$

$=0$. 
Now, from (12) and the above inequalities, we have

$$
\begin{aligned}
& \varepsilon=s\left(\frac{\varepsilon}{s}\right) \leq\left(s \limsup _{i \rightarrow \infty} d\left(x_{m_{i}+1}, x_{n_{i}}\right)\right) \\
& \leq \limsup _{i \rightarrow \infty} \beta\left(d\left(x_{m_{i}}, x_{n_{i}-1}\right)\right) \\
& \times \limsup _{i \rightarrow \infty} M\left(x_{m_{i}}, x_{n_{i}-1}\right) \\
& +L \limsup _{i \rightarrow \infty} N\left(x_{m_{i}}, x_{n_{i}-1}\right) \\
& \leq \varepsilon \limsup _{i \rightarrow \infty} \beta\left(d\left(x_{m_{i}}, x_{n_{i}-1}\right)\right)+0 \leq \frac{1}{s}(\varepsilon),
\end{aligned}
$$

which is a contradiction. So, we conclude that $\left\{x_{n}\right\}$ is a $b$ Cauchy sequence. $b$-Completeness of $X$ yields that $\left\{x_{n}\right\} b$ converges to a point $u \in X$.

Step 3. Now, we show that $u$ is a fixed point of $f$. Since $f$ is continuous, we have

$$
u=\lim _{n \rightarrow \infty} x_{n+1}=\lim _{n \rightarrow \infty} f x_{n}=f u .
$$

Finally, suppose that the set of fixed points of $f$ is well ordered. Assume, on contrary, that $u, v$ are two fixed points for $f$ such that $u \neq v$. Then by (12), we have

$$
\begin{aligned}
s d(u, v) & =s d(f u, f v) \\
& \leq \beta(d(u, v)) M(u, v)+L N(u, v) \\
& =\beta(d(u, v)) d(u, v)<\frac{1}{s} d(u, v)
\end{aligned}
$$

because

$$
\begin{aligned}
M(u, v) & =\max \left\{d(u, v), \frac{d(u, f u) d(v, f v)}{1+d(f u, f v)}\right\} \\
& =\max \{d(u, v), 0\}=d(u, v), \\
N(u, v) & =\min \{d(u, f u), d(u, f v), d(v, f u), d(v, f v)\} \\
& =\min \{0, d(u, v), d(v, u), 0\}=0 .
\end{aligned}
$$

So, we get $s d(u, v)<(1 / s) d(u, v)$, a contradiction. Hence, $u=v$, and $f$ has a unique fixed point. Conversely, if $f$ has a unique fixed point, then the set of fixed points of $f$ is a singleton and is well ordered.

Note that the continuity of $f$ in Theorem 10 is not necessary and can be dropped.

Theorem 11. Under the same hypotheses of Theorem 10, without the continuity assumption of $f$, assume that whenever $\left\{x_{n}\right\}$ is a nondecreasing sequence in $X$ such that $x_{n} \rightarrow u \in X$, one has $x_{n} \preceq u$ for all $n \in \mathbb{N}$. Then, $f$ has a unique fixed point.

Proof. Repeating the proof of Theorem 10, we construct an increasing sequence $\left\{x_{n}\right\}$ in $X$ such that $x_{n} \rightarrow u \in X$. Using the assumption on $X$, we have $x_{n} \preceq u$. Now, we show that $u=$ fu. By Lemma 6, we have

$$
\begin{aligned}
d(u, f u)= & s \frac{1}{s} d(u, f u) \\
\leq & s \limsup _{n \rightarrow \infty} d\left(x_{n+1}, f u\right) \\
\leq & \limsup _{n \rightarrow \infty} \beta\left(d\left(x_{n}, u\right)\right) \limsup _{n \rightarrow \infty} M\left(x_{n}, u\right) \\
& +L \limsup _{n \rightarrow \infty} N\left(x_{n}, u\right),
\end{aligned}
$$

where

$$
\begin{aligned}
& \lim _{n \rightarrow \infty} M\left(x_{n}, u\right) \\
& \quad=\lim _{n \rightarrow \infty} \max \left\{d\left(x_{n}, u\right), \frac{d\left(x_{n}, f x_{n}\right) d(u, f u)}{1+d\left(f x_{n}, f u\right)}\right\} \\
& \quad=\lim _{n \rightarrow \infty} \max \left\{d\left(x_{n}, u\right), \frac{d\left(x_{n}, x_{n+1}\right) d(u, f u)}{1+d\left(x_{n+1}, f u\right)}\right\} \\
& \quad=\max \{0,0\} \\
& \quad=0, \\
& \lim _{n \rightarrow \infty} N\left(x_{n}, u\right) \\
& =\lim _{n \rightarrow \infty} \min \left\{d\left(x_{n}, f u\right), d\left(u, f x_{n}\right), d\left(x_{n}, f x_{n}\right), d(u, f u)\right\} \\
& =\lim _{n \rightarrow \infty} \min \left\{d\left(x_{n}, f u\right), d\left(u, x_{n+1}\right), d\left(x_{n}, x_{n+1}\right), d(u, f u\}\right. \\
& =0 .
\end{aligned}
$$

Therefore, from the above relations, we deduce that $d(u$, $f u)=0$, so, $u=f u$.

If in the above theorems we take $\beta(t)=r$, where $0 \leq r<$ $1 / s$, then we have the following corollary.

Corollary 12. Let $(X, \preceq)$ be a partially ordered set and suppose that there exists a b-metric $d$ on $X$ such that $(X, d)$ is $a b$ complete b-metric space, and let $f: X \rightarrow X$ be an increasing mapping with respect to $\preceq$ such that there exists an element $x_{0} \in$ $X$ with $x_{0} \preceq f\left(x_{0}\right)$. Suppose that

$$
s d(f x, f y) \leq r M(x, y)+L N(x, y)
$$

for all comparable elements $x, y \in X$, where $L \geq 0$,

$$
\begin{gathered}
M(x, y)=\max \left\{d(x, y), \frac{d(x, f x) d(y, f y)}{1+d(f x, f y)}\right\}, \\
N(x, y)=\min \{d(x, f x), d(x, f y), d(y, f x), d(y, f y)\} .
\end{gathered}
$$

If $f$ is continuous or, for any nondecreasing sequence $\left\{x_{n}\right\}$ in $X$ such that $x_{n} \rightarrow u \in X$, one has $x_{n} \preceq u$ for all $n \in N$, then, $f$ has a fixed point. 
Corollary 13. Let $(X, \preceq)$ be a partially ordered set and suppose that there exists a $b$-metric $d$ on $X$ such that $(X, d)$ is a $b$ complete $b$-metric space, and let $f: X \rightarrow X$ be an increasing mapping with respect to $\preceq$ such that there exists an element $x_{0} \in$ $X$ with $x_{0} \preceq f\left(x_{0}\right)$. Suppose that

$$
s d(f x, f y) \leq r \max \left\{d(x, y), \frac{d(x, f x) d(y, f y)}{1+d(f x, f y)}\right\},
$$

for all comparable elements $x, y \in X$, where $0 \leq r<1 / s$. If $f$ is continuous or, for any nondecreasing sequence $\left\{x_{n}\right\}$ in $X$ such that $x_{n} \rightarrow u \in X$, one has $x_{n} \preceq u$ for all $n \in \mathbb{N}$, then, $f$ has a fixed point.

Corollary 14. Let $(X, \preceq)$ be a partially ordered set and suppose that there exists a $b$-metric $d$ on $X$ such that $(X, d)$ is a $b$ complete $b$-metric space, and let $f: X \rightarrow X$ be an increasing mapping with respect to $\preceq$ such that there exists an element $x_{0} \in$ $X$ with $x_{0} \preceq f\left(x_{0}\right)$. Suppose that

$$
s d(f x, f y) \leq a d(x, y)+b \frac{d(x, f x) d(y, f y)}{1+d(f x, f y)},
$$

for all comparable elements $x, y \in X$, where $a, b \geq 0$ and $0 \leq$ $a+b<1 / s$.

If $f$ is continuous or, for any nondecreasing sequence $\left\{x_{n}\right\}$ in $X$ such that $x_{n} \rightarrow u \in X$, one has $x_{n} \preceq u$ for all $n \in N$, then, $f$ has a fixed point.

Proof. Since

$$
\begin{aligned}
& a d(x, y)+b \frac{d(x, f x) d(y, f y)}{1+d(f x, f y)} \\
& \quad \leq(a+b) \max \left\{d(x, y), \frac{d(x, f x) d(y, f y)}{1+d(f x, f y)}\right\},
\end{aligned}
$$

then from (38) we have

$$
s d(f x, f y) \leq r \max \left\{d(x, y), \frac{d(x, f x) d(y, f y)}{1+d(f x, f y)}\right\},
$$

where $r=a+b$. Hence, all the conditions of Corollary 13 hold and $f$ has a fixed point.

Let $\Psi$ be the family of all nondecreasing functions $\psi$ : $[0, \infty) \rightarrow[0, \infty)$ such that

$$
\lim _{n \rightarrow \infty} \psi^{n}(t)=0
$$

for all $t>0$.

Lemma 15 (Berinde [23], Rus [24]). If $\psi \in \Psi$, then the following are satisfied:

(a) $\psi(t)<t$ for all $t>0$;

(b) $\psi(0)=0$.

Example 16. $\psi_{1}(t)=k t$ for all $t \geq 0$, where $k \in[0,1)$, and $\psi_{2}(t)=\ln (t+1)$ for all $t \geq 0$ are in $\Psi$.
Theorem 17. Let $(X, \preceq)$ be a partially ordered set and suppose that there exists a b-metric $d$ on $X$ such that $(X, d)$ is a $b$ complete $b$-metric space, and let $f: X \rightarrow X$ be an increasing mapping with respect to $\preceq$ such that there exists an element $x_{0} \in$ $X$ with $x_{0} \preceq f\left(x_{0}\right)$. Suppose that

$$
s d(f x, f y) \leq \psi(M(x, y)),
$$

where

$$
M(x, y)=\max \left\{d(x, y), \frac{d(x, f x) d(y, f y)}{1+d(f x, f y)}\right\},
$$

for all comparable elements $x, y \in X$. If $f$ is continuous, then $f$ has a fixed point.

Proof. Since $x_{0} \preceq f\left(x_{0}\right)$ and $f$ is an increasing function, we obtain by induction that

$$
x_{0} \preceq f\left(x_{0}\right) \preceq f^{2}\left(x_{0}\right) \preceq \cdots \preceq f^{n}\left(x_{0}\right) \preceq f^{n+1}\left(x_{0}\right) \preceq \cdots .
$$

Putting $x_{n}=f^{n}\left(x_{0}\right)$, we have

$$
x_{0} \preceq x_{1} \preceq x_{2} \preceq \cdots \preceq x_{n} \preceq x_{n+1} \preceq \cdots
$$

If there exists $n_{0} \in \mathbb{N}$ such that $x_{n_{0}}=x_{n_{0}+1}$, then $x_{n_{0}}=f x_{n_{0}}$ and we have nothing to prove. Hence, for all $n \in \mathbb{N}$, we assume $d\left(x_{n}, x_{n+1}\right)>0$.

Step 1. We will prove that

$$
\lim _{n \rightarrow \infty} d\left(x_{n}, x_{n+1}\right)=0 .
$$

Using condition (41), we obtain

$$
\begin{aligned}
d\left(x_{n+1}, x_{n}\right) & \leq s d\left(x_{n+1}, x_{n}\right)=s d\left(f x_{n}, f x_{n-1}\right) \\
& \leq \psi\left(M\left(x_{n}, x_{n-1}\right)\right) .
\end{aligned}
$$

Here,

$$
\begin{aligned}
M & \left(x_{n-1}, x_{n}\right) \\
& =\max \left\{d\left(x_{n-1}, x_{n}\right), \frac{d\left(x_{n-1}, f x_{n-1}\right) d\left(x_{n}, f x_{n}\right)}{1+d\left(f x_{n-1}, f x_{n}\right)}\right\} \\
& =d\left(x_{n-1}, x_{n}\right) .
\end{aligned}
$$

Hence,

$$
d\left(x_{n}, x_{n+1}\right) \leq s d\left(x_{n}, x_{n+1}\right) \leq \psi\left(d\left(x_{n-1}, x_{n}\right)\right) .
$$

By induction,

$$
\begin{aligned}
d\left(x_{n+1}, x_{n}\right) & \leq \psi\left(d\left(x_{n}, x_{n-1}\right)\right) \\
& \leq \psi^{2}\left(d\left(x_{n-1}, x_{n-2}\right)\right) \leq \cdots \leq \psi^{n}\left(d\left(x_{1}, x_{0}\right)\right)
\end{aligned}
$$

As $\psi \in \Psi$, we conclude

$$
\lim _{n \rightarrow \infty} d\left(x_{n}, x_{n+1}\right)=0 .
$$


Step 2. We prove $\left\{x_{n}\right\}$ is a $b$-Cauchy sequence. Suppose the contrary; that is, $\left\{x_{m}\right\}$ is not a $b$-Cauchy sequence. Then, there exists $\varepsilon>0$ for which we can find two subsequences $\left\{x_{m_{i}}\right\}$ and $\left\{x_{n_{i}}\right\}$ of $\left\{x_{n}\right\}$ such that $n_{i}$ is the smallest index for which

$$
n_{i}>m_{i}>i, \quad d\left(x_{m_{i}}, x_{n_{i}}\right) \geq \varepsilon .
$$

This means that

$$
d\left(x_{m_{i}}, x_{n_{i}-1}\right)<\varepsilon .
$$

From (51) and using the triangular inequality, we have

$$
\varepsilon \leq d\left(x_{m_{i}}, x_{n_{i}}\right) \leq s d\left(x_{m_{i}}, x_{m_{i}+1}\right)+s d\left(x_{m_{i}+1}, x_{n_{i}}\right) .
$$

By taking the upper limit as $i \rightarrow \infty$, we have

$$
\frac{\varepsilon}{s} \leq \limsup _{i \rightarrow \infty} d\left(x_{m_{i}+1}, x_{n_{i}}\right) \text {. }
$$

Using the triangular inequality, we have

$$
d\left(x_{m_{i}}, x_{n_{i}}\right) \leq s d\left(x_{m_{i}}, x_{n_{i}-1}\right)+s d\left(x_{n_{i}-1}, x_{n_{i}}\right) .
$$

Taking the upper limit as $i \rightarrow \infty$ in the above inequality and using (52), we get

$$
\limsup _{i \rightarrow \infty} d\left(x_{m_{i}}, x_{n_{i}}\right) \leq \varepsilon s .
$$

From the definition of $M(x, y)$,

$$
\begin{aligned}
M & \left(x_{m_{i}}, x_{n_{i}-1}\right) \\
& =\max \left\{d\left(x_{m_{i}}, x_{n_{i-1}}\right), \frac{d\left(x_{m_{i}}, f x_{m_{i}}\right) d\left(x_{n_{i-1}}, f x_{n_{i-1}}\right)}{1+d\left(f x_{m_{i}}, f x_{n_{i-1}}\right)}\right\} \\
& =\left\{d\left(x_{m_{i}}, x_{n_{i-1}}\right), \frac{d\left(x_{m_{i}}, x_{m_{i+1}}\right) d\left(x_{n_{i-1}}, x_{n_{i}}\right)}{1+d\left(x_{m_{i+1}}, x_{n_{i}}\right)}\right\} .
\end{aligned}
$$

If $i \rightarrow \infty$, by (50) and (52), then we have

$$
\limsup _{i \rightarrow \infty} M\left(x_{m_{i}}, x_{n_{i}-1}\right) \leq \varepsilon .
$$

Now, from (41), we have

$$
\begin{aligned}
s d\left(x_{m_{i+1}}, x_{n_{i}}\right) & =s d\left(f x_{m_{i}}, f x_{n_{i-1}}\right) \\
& \leq \psi\left(M\left(x_{m_{i}}, x_{n_{i-1}}\right)\right) .
\end{aligned}
$$

Again, if $i \rightarrow \infty$, by (52) and (54), we obtain

$$
\varepsilon=s\left(\frac{\varepsilon}{s}\right) \leq\left(s \limsup _{i \rightarrow \infty} d\left(x_{m_{i+1}}, x_{n_{i}}\right)\right) \leq \psi(\varepsilon)<\varepsilon
$$

which is a contradiction. Thus, $\left\{x_{n}\right\}$ is a $b$-Cauchy sequence. Completeness of $X$ yields that $\left\{x_{n}\right\}$ converges to a point $u \in$ $X$; that is, $x_{n} \rightarrow u$ as $n \rightarrow \infty$.

Step 3. Now, we show that $u$ is a fixed point of $f$. Since, $f$ is continuous, we have

$$
u=\lim _{n \rightarrow \infty} x_{n+1}=\lim _{n \rightarrow \infty} f x_{n}=f u .
$$

So, $u$ is a fixed point of $f$.
Theorem 18. Under the same hypotheses of Theorem 17, without the continuity assumption of $f$, assume that whenever $\left\{x_{n}\right\}$ is a nondecreasing sequence in $X$ such that $x_{n} \rightarrow u \in X, x_{n} \preceq$ $u$ for all $n \in \mathbb{N}$. Then, $f$ has a fixed point.

Proof. Repeating the proof of Theorem 17, we construct an increasing sequence $\left\{x_{n}\right\}$ in $X$ such that $x_{n} \rightarrow u \in X$. Using the assumption on $X$, we have $x_{n} \preceq u$. Now, we show that $u=$ fu. By (41), we have

$$
s d\left(f u, x_{n}\right)=s d\left(f u, f x_{n-1}\right) \leq \psi\left(M\left(u, x_{n-1}\right)\right),
$$

where

$$
\begin{aligned}
M\left(u, x_{n-1}\right) & =\max \left\{d\left(u, x_{n-1}\right), \frac{d(u, f u) d\left(x_{n-1}, f x_{n-1}\right)}{1+d\left(f u, f x_{n-1}\right)}\right\} \\
& =\max \left\{d\left(u, x_{n-1}\right), \frac{d(u, f u) d\left(x_{n-1}, x_{n}\right)}{1+d\left(f u, x_{n-1}\right)}\right\} .
\end{aligned}
$$

Letting $n \rightarrow \infty$ in (63), we get

$$
\limsup _{n \rightarrow \infty} M\left(u, x_{n-1}\right)=0 \text {. }
$$

Again, taking the upper limit as $n \rightarrow \infty$ in (62) and using Lemma 6 and (64), we get

$$
\begin{aligned}
d(f u, u) & =s \frac{1}{s} d(f u, u) \\
& \leq \underset{n}{\limsup } d\left(f u, x_{n}\right) \\
& \leq \limsup _{n \rightarrow \infty} \psi\left(M\left(u, x_{n-1}\right)\right) \\
& =0 .
\end{aligned}
$$

So, we get $d(f u, u)=0$. That is, $f u=u$.

\section{Coincidence Point Results}

Lemma 19 (see [25]). Let $X$ be a nonempty set and let $f$ : $X \rightarrow X$ be a function. Then, there exists a subset $E \subseteq X$ such that $f(E)=f(X)$ and $f: E \rightarrow X$ is one-to-one.

Theorem 20. Let $(X, \preceq)$ be a partially ordered set and suppose that there exists a b-metric $d$ on $X$ such that $(X, d)$ is $a b$ complete b-metric space, and let $f, T: X \rightarrow X$ be such that $f$ is an increasing mapping with respect to $T, f X \subseteq T X$ and there exists an element $x_{0} \in X$ with $T x_{0} \preceq f x_{0}$. Suppose that $(T, f)$ satisfies the following condition

$$
s d(f x, f y) \leq \beta(d(T x, T y)) M^{T}(x, y)+L N^{T}(x, y),
$$

for all comparable elements $x, y \in X$, where $L \geq 0$,

$$
\begin{gathered}
M^{T}(x, y)=\max \left\{d(T x, T y), \frac{d(T x, f x) d(T y, f y)}{1+d(f x, f y)}\right\}, \\
N^{T}(x, y)=\min \{d(T x, f x), d(T x, f y), \\
d(T y, f x), d(T y, f y)\} .
\end{gathered}
$$

If $f$ is continuous, then $(f, T)$ has a coincidence point. 
Proof. Let $f: X \rightarrow X$. From Lemma 19 there exists $E \subset X$ such that $f(E)=f(X)$ and $\left.f\right|_{E}$ is one-to-one. Since $T(E) \subseteq$ $T(X) \subseteq X$, we can define the mapping $\mathscr{A}: T(E) \rightarrow X$ by $\mathscr{A}(T x)=f x$, for all $x \in E$. Since $\left.f\right|_{E}$ is one-to-one, then $\mathscr{A}$ is well defined. Now, since $(f, T)$ satisfies (66), we have

$$
\begin{aligned}
s d & (\mathscr{A}(T x), \mathscr{A}(T y)) \\
& =s d(f x, f y) \\
& \leq \beta(d(T x, T y)) M^{T}(x, y)+L N^{T}(x, y),
\end{aligned}
$$

for all $x, y \in X$, where

$$
\begin{gathered}
M^{T}(x, y) \\
=\max \left\{d(T x, T y), \frac{d(T x, \mathscr{A}(f x)) d(T y, \mathscr{A}(f y))}{1+d(\mathscr{A}(f x), \mathscr{A}(f y))}\right\}, \\
N^{T}(x, y)=\min \{d(T x, \mathscr{A}(f x)), d(T y, \mathscr{A}(f y)), \\
d(T x, \mathscr{A}(f y)), d(T y, \mathscr{A}(f x))\} .
\end{gathered}
$$

This shows that $\mathscr{A}$ satisfies the condition of Theorem 10. So, there exists fixed point $u \in T(E)$ of $\mathscr{A}$; that is, $\mathscr{A} u=u$. Since $u \in T(E)$, then there exists $w \in E$ such that

$$
f w=\mathscr{A}(T w)=\mathscr{A} u=u=T w .
$$

That is, $w$ is a coincidence point of $f$ and $T$.

Theorem 21. Under the same hypotheses of Theorem 20, without the continuity assumption of $f$, assume that whenever $\left\{x_{n}\right\}$ is a nondecreasing sequence in $X$ such that $x_{n} \rightarrow u \in X, x_{n} \preceq$ $u$ for all $n \in \mathbb{N}$. Then, $(f, T)$ has a coincidence point.

Theorem 22. Let $(X, \preceq)$ be a partially ordered set and suppose that there exists a b-metric $d$ on $X$ such that $(X, d)$ is $a b$ complete $b$-metric space, and let $f, T: X \rightarrow X$ be such that $f$ is an increasing mapping with respect to $T, f X \subseteq T X$ and there exists an element $x_{0} \in X$ with $T x_{0} \preceq f x_{0}$. Suppose that

$$
s d(f x, f y) \leq \psi\left(M^{T}(x, y)\right),
$$

where

$$
M^{T}(x, y)=\max \left\{d(T x, T y), \frac{d(T x, f x) d(T y, f y)}{1+d(f x, f y)}\right\},
$$

for all comparable elements $x, y \in X$. If $f$ is continuous, then $(f, T)$ has a coincidence point.

Theorem 23. Under the same hypotheses of Theorem 22, without the continuity assumption of $f$, assume that whenever $\left\{x_{n}\right\}$ is a nondecreasing sequence in $X$ such that $x_{n} \rightarrow u \in X, x_{n} \preceq$ $u$ for all $n \in \mathbb{N}$. Then $(f, T)$ has a fixed point.

Remark 24. Taking $s=1$, our obtained results coincide with the results in usual metric case. Also, Theorems 10 and 11 are extensions of Theorem 3.8 of [22] and Theorem 8 .
Example 25. Let $X=\{0,1,3\}$ and define the partial order $\preceq$ on $X$ by

$$
\preceq:=\{(0,0),(1,1),(3,3),(0,3),(3,1),(0,1)\} .
$$

Consider the function $f: X \rightarrow X$ given as

$$
\mathbf{f}=\left(\begin{array}{lll}
0 & 1 & 3 \\
3 & 1 & 1
\end{array}\right)
$$

which is increasing with respect to $\preceq$. Let $x_{0}=0$. Hence, $f\left(x_{0}\right)=3$, so $x_{0} \preceq f x_{0}$. Define first the $b$-metric $d$ on $X$ by $d(0,1)=6, d(0,3)=9, d(1,3)=1 / 2$, and $d(x, x)=0$. Then, $(X, d)$ is a $b$-complete $b$-metric space with $s=18 / 13$ and the function $\beta \in \mathscr{F}$ given by

$$
\beta(t)=\frac{13}{18} e^{-t / 9}, \quad t \geq 0
$$

and $\beta(0) \in[0,13 / 18)$ and $L \geq 0$ is arbitrary. Then,

$$
\begin{aligned}
s d(f 0, f 3)= & \frac{18}{13} d(3,1)=\frac{18}{13} \cdot \frac{1}{2} \\
\leq & \beta(d(0,3)) M(0,3) \\
& +L N(0,3) \leq \beta(9) M(0,3) \\
& +L N(0,3)=\beta(9) 9
\end{aligned}
$$

because

$$
\begin{aligned}
M(0,3) & =\max \left\{d(0,3), \frac{d(0, f 0) d(3, f 3)}{1+d(f 0, f 3)}\right\} \\
& =\max \left\{d(0,3), \frac{d(0,3) d(3,1)}{1+d(3,1)}\right\}=9, \\
N(0,3) & =\min \{d(0, f 0), d(3, f 3), d(3, f 0), d(0, f 3)\} \\
& =\min \{d(0,3), d(3,1), d(3,3), d(0,1)\}=0 .
\end{aligned}
$$

Also,

$$
\begin{aligned}
s d(f 0, f 1) & =\frac{18}{13} d(3,1)=\frac{18}{13} \cdot \frac{1}{2} \\
& \leq \beta(d(0,1)) M(0,1)+\operatorname{LN}(0,1) \\
& \leq \beta(6) M(0,1)+\operatorname{LN}(0,1)=\beta(6) 6
\end{aligned}
$$

because

$$
\begin{aligned}
M(0,1) & =\max \left\{d(0,1), \frac{d(0, f 0) d(1, f 1)}{1+d(f 0, f 1)}\right\} \\
& =\max \left\{d(0,1), \frac{d(0,3) d(1,1)}{1+d(3,1)}\right\}=6 .
\end{aligned}
$$

Also,

$$
\begin{aligned}
s d(f 1, f 3) & =\frac{18}{13} d(1,1)=0 \\
& \leq \beta(d(1,3)) M(1,3)+\operatorname{LN}(1,3) .
\end{aligned}
$$

Hence, $f$ satisfies all the assumptions of Theorem 10 and thus it has a fixed point (which is $u=1$ ). 


\section{Existence Theorem for a Solution of an Integral Equation}

Consider the integral equation

$$
x(t)=p(t)+\int_{0}^{T} \lambda(t, r) f(r, x(r)) d r, \quad t \in[0, T],
$$

where $T>0$. The purpose of this section is to give an existence theorem for a solution of (81) that belongs to $X=C(I$, $\mathbb{R}$ ) (the set of continuous real functions defined on $I=[0, T]$, by using the obtained result in Theorem 17). Obviously, this space with the $b$-metric given by

$$
d(x, y)=\max _{t \in I}|x(t)-y(t)|^{p},
$$

for all $x, y \in X$, is a $b$-complete $b$-metric space with $s=2^{p-1}$ and $p \geq 1$.

We endow $X$ with the partial order $\preceq$ given by

$$
x \preceq y \Longleftrightarrow x(t) \leq y(t),
$$

for all $t \in I$. It was proved in [3] that $(X, \preceq, d)$ is regular (the proof is valid also in the $b$-metric case). We will consider (81) under the following assumptions:

(i) $f, p:[0, T] \times \mathbb{R} \rightarrow \mathbb{R}$ are continuous,

(ii) $\lambda:[0, T] \times \mathbb{R} \rightarrow[0, \infty)$ is continuous,

(iii) there exist $q>0$ such that for all $x, y$ with $x \preceq y$

$$
0 \leq f(r, y)-f(r, x) \leq q(y-x),
$$

(iv) $\max _{t \in I}\left(\int_{0}^{T}|\lambda(t, r)| d r\right)^{p} \leq 1 / 2^{2 p-2} q^{p}$,

(v) there exists continuous function $\alpha:[0, T] \rightarrow \mathbb{R}$ such that

$$
\alpha(t) \leq p(t)+\int_{0}^{T} \lambda(t, r) f(r, \alpha(r)) d r .
$$

Theorem 26. Under assumptions (i)-(v), (81) has a solution in $X$, where $X=C([0, T], \mathbb{R})$.

Proof. We define $F: X \rightarrow X$ by

$$
F(x(t))=p(t)+\int_{0}^{T} \lambda(t, r) f(r, x(r)) d r .
$$

The mapping $F$ is increasing since, for $x \preceq y$,

$$
f(t, x) \leq f(t, y),
$$

and from $\lambda(t, r)>0$, we have

$$
\begin{aligned}
F(x(t)) & =p(t)+\int_{0}^{T} \lambda(t, r) f(r, x(r)) d r \\
& \leq p(t)+\int_{0}^{T} \lambda(t, r) f(r, y(r)) d r=F(y(t)) .
\end{aligned}
$$

Now, we have

$$
\begin{aligned}
& 2^{p-1}|F x(t)-F y(t)|^{p} \\
& \quad=2^{p-1}\left|\int_{0}^{T} \lambda(t, r)[f(r, x(r))-f(r, y(r))] d r\right|^{p} \\
& \quad \leq 2^{p-1}\left(\int_{0}^{T}|\lambda(t, r)[f(r, x(r))-f(r, y(r))]| d r\right)^{p} \\
& \quad \leq 2^{p-1} q^{p}\left(\max _{r \in I}|x(r)-y(r)|\right)^{p}\left(\int_{0}^{T}|\lambda(t, r)| d r\right)^{p} \\
& \quad \leq 2^{p-1} q^{p} d(x, y) \frac{1}{2^{2 p-2} q^{p}} \\
& \quad \leq \frac{1}{2^{p-1}} M(x, y),
\end{aligned}
$$

where

$$
M(x, y)=\max \left\{d(x, y), \frac{d(x, F x) d(y, F y)}{1+d(F x, F y)}\right\} .
$$

Let $\alpha$ be the function appearing in assumption (v). Then, we get

$$
\alpha \preceq F(\alpha)
$$

Thus, from Theorem 17, by $\psi(t)=(1 / s) t=\left(1 / 2^{p-1}\right) t$, we deduce the existence of $x \in X$ such that $x=F(x)$.

\section{Conflict of Interests}

The authors declare that there is no conflict of interests regarding the publication of this paper.

\section{References}

[1] M. Abbas, V. Parvaneh, and A. Razani, "Periodic points of $T$-Ciric generalized contraction mappings in ordered metric spaces," Georgian Mathematical Journal, vol. 19, no. 4, pp. 597610, 2012.

[2] J. J. Nieto and R. Rodríguez-López, "Contractive mapping theorems in partially ordered sets and applications to ordinary differential equations," Order, vol. 22, no. 3, pp. 223-239, 2005.

[3] J. J. Nieto and R. Rodríguez-López, "Existence and uniqueness of fixed point in partially ordered sets and applications to ordinary differential equations," Acta Mathematica Sinica, vol. 23, no. 12, pp. 2205-2212, 2007.

[4] A. C. M. Ran and M. C. B. Reurings, "A fixed point theorem in partially ordered sets and some applications to matrix equations," Proceedings of the American Mathematical Society, vol. 132, no. 5, pp. 1435-1443, 2004.

[5] S. Czerwik, "Contraction mappings in b-metric spaces," Acta Mathematica et Informatica Universitatis Ostraviensis, vol. 1, pp. 5-11, 1993.

[6] H. Aydi, M. Bota, E. Karapnar, and S. Mitrović, "A fixed point theorem for set-valued quasicontractions in $b$-metric spaces," Fixed Point Theory and Applications, vol. 2012, article 88, 2012. 
[7] N. Hussain, V. Parvaneh, J. R. Roshan, and Z. Kadelburg, "Fixed points of cyclic weakly $(\psi, \phi, L, A, B)$-contractive mappings in ordered $b$-metric spaces with applications," Fixed Point Theory and Applications, vol. 2013, article 256, 2013.

[8] N. Hussain, J. R. Roshan, V. Parvaneh, and M. Abbas, "Common fixed point results for weak contractive mappings in ordered bdislocated metric spaces with applications," Journal of Inequalities and Applications, vol. 2013, article 486, 2013.

[9] M. O. Olatinwo, "Some results on multi-valued weakly Jungck mappings in b-metric space," Central European Journal of Mathematics, vol. 6, no. 4, pp. 610-621, 2008.

[10] M. Păcurar, "Sequences of almost contractions and fixed points in b-metric spaces," Analele. Universităţii de Vest din Timişoara. Seria Matematică-Informatică, vol. 48, no. 3, pp. 125-137, 2010.

[11] V. Parvaneh, J. R. Roshan, and S. Radenović, "Existence of tripled coincidence points in ordered $b$-metric spaces and an application to a system of integral equations," Fixed Point Theory and Applications, vol. 2013, article 19, 2013.

[12] S. Radenović, M. Jovanović, and Z. Kadelburg, "Common fixed point results in metric-type spaces," Fixed Point Theory and Applications, vol. 2010, Article ID 978121, 15 pages, 2010.

[13] M. A. Khamsi, "Remarks on cone metric spaces and fixed point theorems of contractive mappings," Fixed Point Theory and Applications, vol. 2010, Article ID 315398, 7 pages, 2010.

[14] Z. Mustafa, J. R. Roshan, V. Parvaneh, and Z. Kadelburg, "Fixed point theorems for weakly T-Chatterjea and weakly T-Kannan contractions in b-metric spaces," Journal of Inequalities and Applications, vol. 2014, article 46, 2014.

[15] Z. Mustafa, J. R. Roshan, V. Parvaneh, and Z. Kadelburg, "Some common fixed point results in ordered partial $b$-metric spaces," Journal of Inequalities and Applications, vol. 2013, article 562, 2013.

[16] A. Aghajani, M. Abbas, and J. R. Roshan, "Common fixed point of generalized weak contractive mappings in partially ordered b-metric spaces," Mathematica Slovaca. In press.

[17] M. Boriceanu, "Strict fixed point theorems for multivalued operators in b-metric spaces," International Journal of Modern Mathematics, vol. 4, no. 3, pp. 285-301, 2009.

[18] N. Hussain, D. Dorić, Z. Kadelburg, and S. Radenović, "Suzukitype fixed point results in metric type spaces," Fixed Point Theory and Applications, vol. 2012, article 126, 2012.

[19] M. A. Geraghty, "On contractive mappings," Proceedings of the American Mathematical Society, vol. 40, pp. 604-608, 1973.

[20] A. Amini-Harandi and H. Emami, "A fixed point theorem for contraction type maps in partially ordered metric spaces and application to ordinary differential equations," Nonlinear Analysis: Theory, Methods and Applications, vol. 72, no. 5, pp. 22382242, 2010.

[21] J. Caballero, J. Harjani, and K. Sadarangani, "A best proximity point theorem for Geraghty-contractions," Fixed Point Theory and Applications, vol. 2012, article 231, 2012.

[22] D. Dukić, Z. Kadelburg, and S. Radenović, "Fixed points of Geraghty-type mappings in various generalized metric spaces," Abstract and Applied Analysis, vol. 2011, Article ID 561245, 13 pages, 2011.

[23] V. Berinde, Contracții generalizate şi aplicaţii, vol. 2, Editura Cub Press, Baia Mare, Romania, 1997.

[24] I. A. Rus, Generalized Contractions and Applications, Cluj University Press, Cluj-Napoca, Romania, 2001.

[25] R. H. Haghi, S. Rezapour, and N. Shahzad, "Some fixed point generalizations are not real generalizations," Nonlinear Analysis: Theory, Methods and Applications, vol. 74, no. 5, pp. 1799-1803, 2011. 


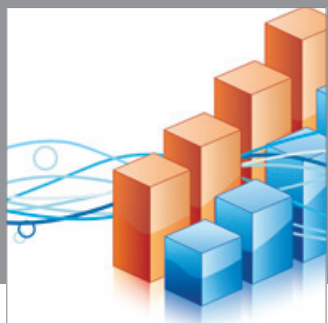

Advances in

Operations Research

mansans

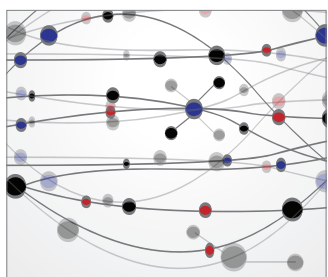

The Scientific World Journal
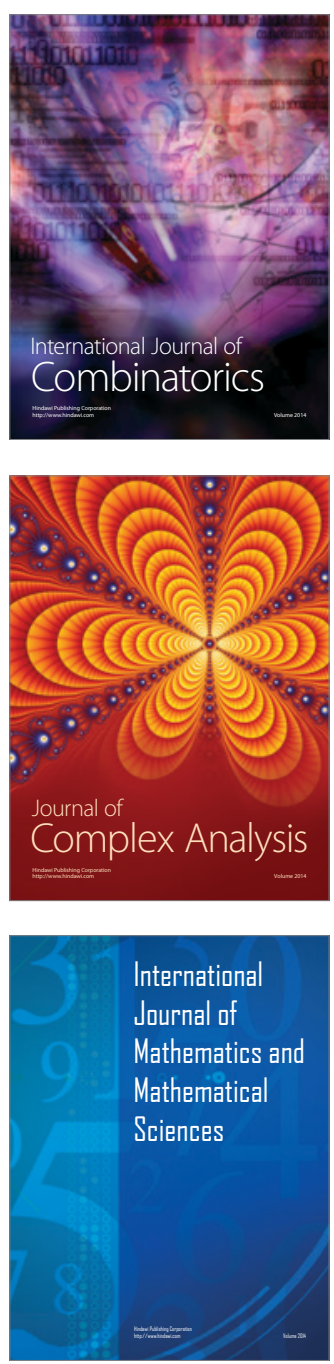
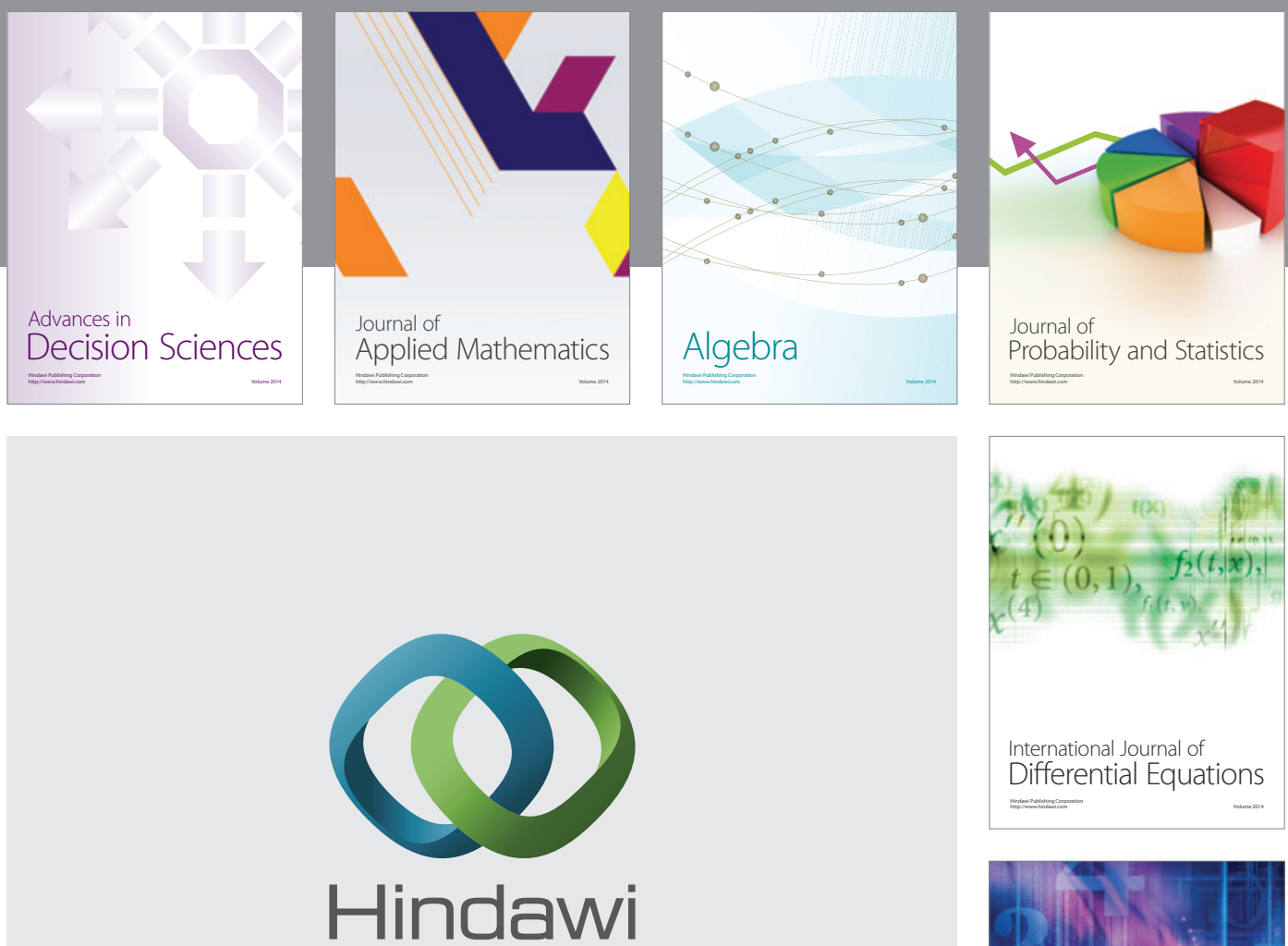

Submit your manuscripts at http://www.hindawi.com
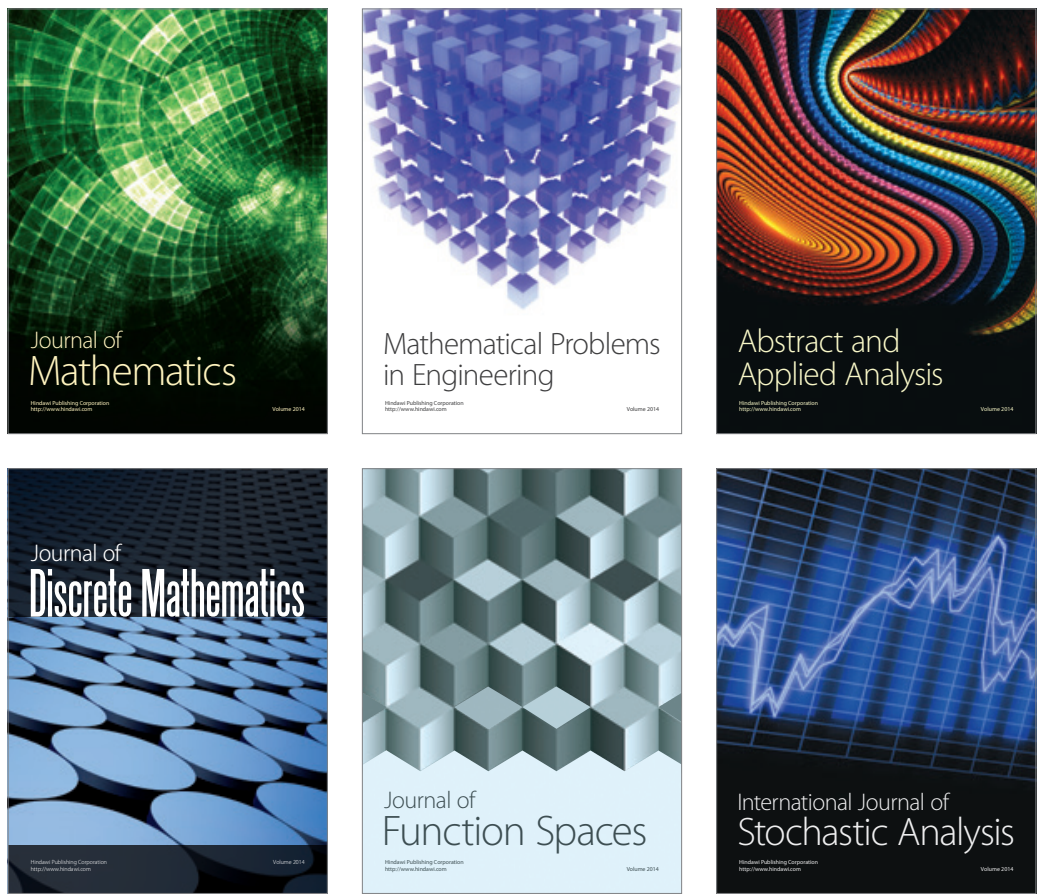

Journal of

Function Spaces

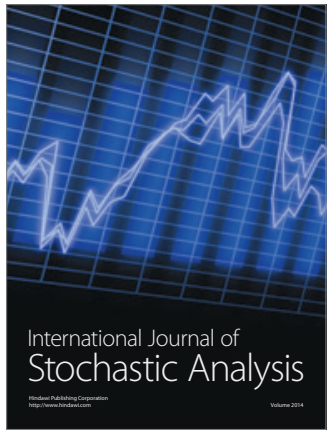

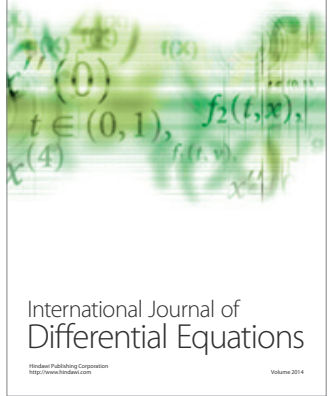
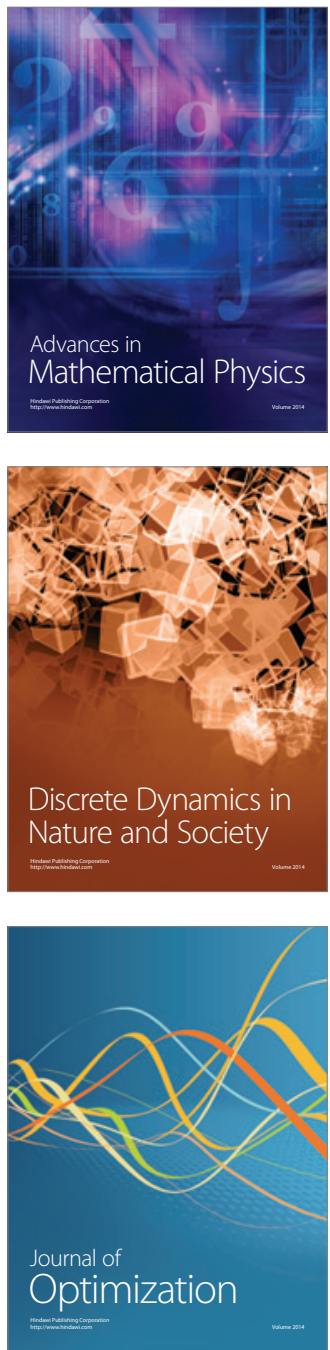